\title{
Does alcohol intoxication precipitate aneurysmal subarachnoid haemorrhage?
}

\author{
MA T T I H ILLBOM A N D A RKKU KASTE \\ From the Department of Neurology, University of Helsinki
}

S U M M ARY Seventy-five consecutive patients aged 15 to 55 years with aneurysmal subarachnoid haemorrhage verified by CSF examination and cerebral angiography or at necropsy were studied. In 19 cases ( $25 \%$; four women and 15 men) the bleeding was preceded within 24 hours by a bout of alcohol drinking. Alcohol-related cases composed $33 \%$ and $14 \%$ of the patients in the age groups 15-40 and 41-55 years, respectively. Alcohol intoxication preceding the subarachnoid haemorrhage was two to four times as common in male and three to five times as common in female patients as alcohol intoxication in the general Finnish population of the same age and sex. Occasional alcohol intoxication seems to carry an increased risk of aneurysmal subarachnoid haemorrhage.

We were impressed by the number of cases of aneurysmal subarachnoid haemorrhage in which the bleeding was preceded by alcohol intoxication. Some observations suggest that haemorrhagic strokes are frequent among alcohol misusers, ${ }^{12}$ and there is evidence to show that alcohol intoxication is frequently associated with traumatic subarachnoid haemorrhage provoked by minor head injuries. ${ }^{3}$ Occasional alcohol intoxication has not previously been recognised as a risk factor in spontaneous aneurysmal subarachnoid haemorrhage. In order to see whether occasional alcohol intoxication increases the risk of nontraumatic aneurysmal subarachnoid haemorrhage we started a prospective study at the beginning of 1978 .

\section{Patients and methods}

All consecutive patients aged 15 to 55 years who were admitted to the Department of Neurology, University of Helsinki, since the beginning of January 1978 for a subarachnoid haemorrhage due to aneurysm verified by cerebrospinal fluid (CSF) examination and cerebral angiography or at necropsy were included. The only patients excluded were those admitted because of recurrent bleeding and those who died within the first 24 hours without regaining consciousness. The study comprised data from 36 female and 39 male patients.

The patients were asked about previous diseases, drinking and smoking habits and for such recent

Address for reprint requests: Dr Matti Hillbom, Department of Neurology, University of Helsinki, SF-00290 Helsinki 29, Finland. Accepted 10 March 1981 events preceding the onset of the symptoms as alcohol intoxication, use of drugs, head trauma and physical exertion including coitus, defaecation and vomiting. In many cases the data were obtained from or confirmed by the relatives or friends of the patients. Aneurysmal bleedings among close relatives were also charted. The term "alcohol-related subarachnoid haemorrhage" is reserved here for cases in which the first symptoms of subarachnoid haemorrhage were preceded within 24 hours by moderate to severe alcohol intoxication. All patients who were considered as having been intoxicated had consumed the equivalent of at least $80 \mathrm{~g}$ of absolute alcohol within a few hours; by a heavy drinker we mean a person who takes more than five drinks per day almost daily. The daily alcohol intoxication rates in different age-groups in our patients were compared with the equivalent figures for the general Finnish population, 4 and the percentages of subarachnoid haemorrhage occurring on different weekdays were compared with the weekly rhythm of alcohol consumption in Finland. ${ }^{5}$

The results were compared with the findings of Finnish population studies. ${ }^{4-7}$ Chi-square test with Yates correction was used in statistical comparisons.

\section{Results}

Alcohol intoxication preceded symptoms of subarachnoid haemorrhage in $19(25 \%)$ of our 75 patients. Five of them were stricken while still intoxicated, and the other 14 within 24 hours. The age and sex distribution of the patients is shown in fig 1 . The alcohol-related cases were $33 \%$ and $14 \%$ of the patients in age-groups $15-40$, and $41-$ 


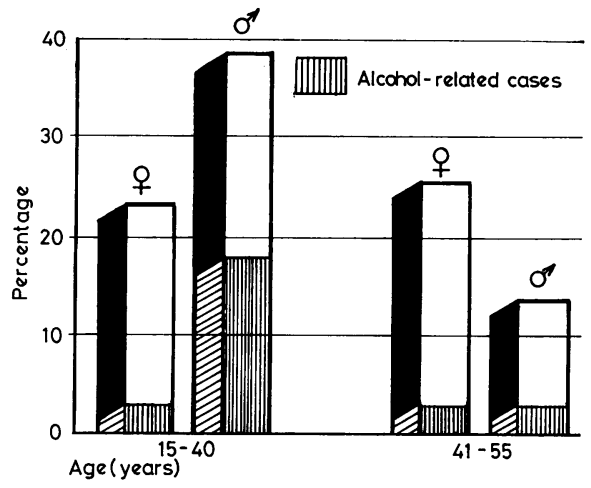

Fig 1 Percentage distribution of patients by age and sex.

55 years, respectively, representing $45 \%$ and $20 \%$ of the male patients and $12 \%$ and $10 \%$ of the female patients. The daily alcohol intoxication rates in the Finnish population of age-groups $15-40$ and $41-55$ years are $12 \%$ and $10 \%$ in men and $4 \%$ and $2 \%$ in women, respectively. ${ }^{4}$ Accordingly, alcohol intoxication preceding the bleeding was two to four times as common in male and three to five times as common in female patients as alcohol intoxication in the general Finnish population of the same age and sex. Men were over-represented among the alcohol-related cases probably because they drink about $80 \%$ of all alcoholic beverages in Finland. ${ }^{4}$ Especially young men were frequently stricken after a drinking bout. Among the patients under the age of 40 years they had alcohol-related bleedings (13 of 29 cases) significantly more often than women ( 2 of 17 cases $)\left(\chi^{2}=3.93, p<0.05\right)$.

The percentage distribution of onset of subarachnoid haemorrhage on different days of the week was compared with the weekly rhythm of alcohol consumption in Finland (fig 2). Alzohol consumption on Fridays is almost double, and on Saturdays treble that on any other day of the week. ${ }^{5}$ Therefore, if alcohol intoxication does promote aneurysmal subarachnoid bleeding, cases related to intoxication should accumulate on weekends, which in fact proved to be the case. The percentage distribution of subarachnoid haemorrhage on different days followed the weekly rhythm of alcohol consumption. Chi-square analysis was used in evaluating day of admission, assuming that admissions on Saturday and Sunday should have been only two sevenths of the total. Thirty-five of our 75 consecutive cases were admitted during these days $\left(\chi^{2}=4 \cdot 82, p<0 \cdot 05\right)$, and the corresponding figures for the alcohol-related

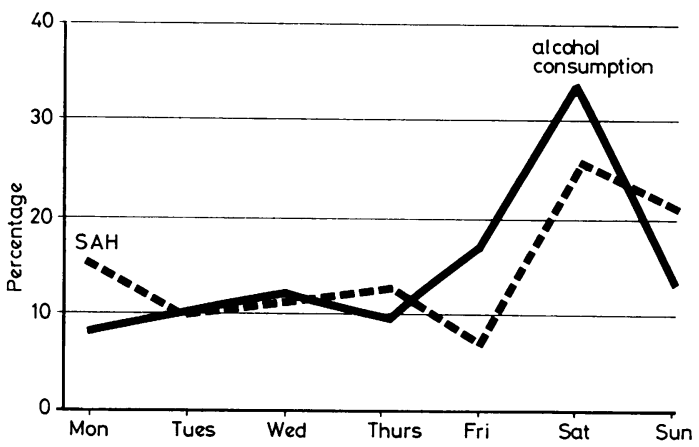

Fig 2 Distribution of aneurysmal subarachnoid haemorrhage $(\mathrm{SAH})$ on different weekdays (percentage of cases), compared with alcohol consumption in general population. 5

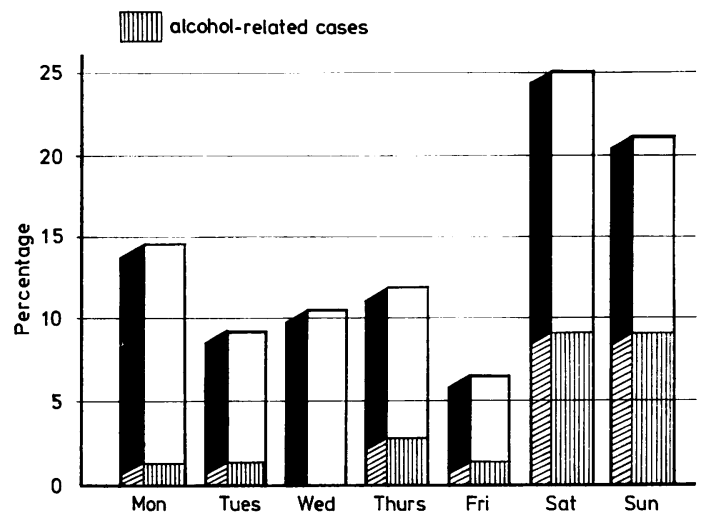

Fig 3 Distribution of aneurysmal subarachnoid haemorrhage on different weekdays (percentage of cases).

cases were 14 of $19\left(\chi^{2}=6 \cdot 74, \mathrm{p}<0.05\right)$. In contrast, admissions of the alcohol-unrelated cases occurred fairly evenly throughout the week (fig 3 ).

Six women and eight men were heavy drinkers. The proportion of heavy drinkers $(19 \%)$ was higher in our series than in the general Finnish population of the same age $(7 \%)$. Eight of the heavy drinkers had alcohol-related bleeds, and heavy drinking was more common $\left(\chi^{2}=7 \cdot 26\right.$, $\mathrm{p}<0.01$ ) among the alcohol-related cases (eight of 19 cases) than among the others (six of 56 cases). The incidence of alcohol intoxication and other known or possible risk factors in our 75 patients are shown in the table. Finnish population studies have revealed broadly similar prevalences of smoking, ${ }^{6}$ migraine ${ }^{7}$ and arterial hypertension. ${ }^{6}$ Arterial hypertension and smoking were equally common among both groups of patients. 
Table The incidence of risk factors in the 75 patients

\begin{tabular}{ll}
\hline Risk factor & Number of patients \\
\hline Smoking & $44(59 \%)$ \\
Physical exertion & $25(33 \%)$ \\
Arterial hypertension & $23(31 \%)$ \\
Alcohol intoxication & $19(25 \%)$ \\
Migraine & $17(23 \%)$ \\
Heavy drinking & $14(19 \%)$ \\
SAH in close relatives & $14(19 \%)$ \\
\hline
\end{tabular}

Twenty-five patients suffered the first symptoms while undergoing some kind of exertion, such as coitus in $11(15 \%)$ and defaecation in eight cases $(11 \%)$. The remaining six patients $(8 \%)$, all of whom were men, reported such pursuits as running, rowing a boat, sawing planks, clearing snow or lifting some burden. These activities occurred evenly throughout the week and were not concentrated on the alcohol-related cases. Men reported physical exercise more often $\left(x^{2}=7 \cdot 27\right.$, $\mathrm{p}<0.01)$ than women $(19$ of 39 versus 6 of 36 ).

We also examined whether alcohol intoxication or heavy drinking influenced the short-term prognosis of our patients. Twenty-three of the 75 patients $(31 \%)$ died within a month from the bleeding. Mortality of the alcohol-related cases was $26 \%$ (five of 19 ) while that of the alcoholunreleated cases was $32 \%$ (18 of 56 ), but the difference was not statistically significant. Women had a greater mortality than men (39 versus $23 \%$ ).

\section{Discussion}

Alcohol intoxication has not previously been recognised as a risk factor in aneurysmal subarachnoid haemorrhage, although some observations have suggested that haemorrhagic strokes are frequent among alcohol misusers, ${ }^{12}$ and in one series intoxicated persons composed $12 \%$ of the patients who succumbed to aneurysmal bleeding. ${ }^{3}$ In one fourth of our patients with aneurysmal subarachnoid haemorrhage the onset of symptoms was preceded by alcohol intoxication, and the results indicate that occasional alcohol intoxication increases the risk of aneurysmal subarachnoid haemorrhage for both men and women. Our data also indicate that subarachnoid haemorrhage concentrates at weekends, and suggest that this is probably due to the drinking habits in our country.

Women have a higher incidence of subarachnoid haemorrhage in the older age-groups, while men are more frequent in the younger age-groups. ${ }^{8}$ If alcohol intoxication is a risk factor of subarachnoid haemorrhage, differences in drinking habits could be one reason for the uneven distribution of subarachnoid haemorrhage in the various age and sex groups. Men drink about four-fifths of all alcoholic beverages in Finland, and heavy drinking is several times more frequent among young men than among young women. ${ }^{4}$

"Valsalva situations" including vomiting and defaecation as well as physical exercise including coitus were equally common among the alcoholrelated and the alcohol-unrelated cases. Our observations thus suggest that alcohol intoxication itself rather than other activities combined with it carries a risk of subarachnoid haemorrhage. Of the other possible risk factors, the prevalences of arterial hypertension, smoking and migraine in our patients were similar to those of Finnish population studies. ${ }^{67}$ Although smoking and arterial hypertension are associated with heavy drinking, ${ }^{910}$ they were not more prevalent among the alcohol-related than the alcohol-unrelated cases in the present study.

The suggestion that alcohol intoxication is a risk factor in aneurysmal subarachnoid haemorrhage does not necessarily imply a causal relationship. Some experimental data indicate that cerebral circulation is significantly influenced by alcohol intoxication. Acute moderate intoxication may cause short-lasting vasodilation and cerebral hyperaemia. ${ }^{1112}$ On the other hand, prolonged intoxication may result in increased cerebral blood flow when the alcohol withdrawal symptoms appear. ${ }^{13}$ In conclusion, it seems that occasional alcohol intoxication is associated with an increased risk of aneurysmal subarachnoid haemorrhage.

This study was supported by the Paavo Nurmi Foundation, Finland and the Finnish Foundation for Alcohol Studies, Finland.

\section{References}

1 Tarasyuk IK. The effect of alcohol misuse on the development and course of acute brain circulation disorders. Zh Nevropat Psikhiat 1976; 76:1777-80.

2 Romanova MV, Romanov NS. Cerebral circulation disturbances in patients with chronic alcoholism. Sov Med 1978; 7:148-9.

3 Simonsen J. Traumatic subarachnoid hemorrhage in alcohol intoxication. J Forens Sci 1963; 8: 97-116.

4 Simpura J. Finnish drinking habits in 1969 and 1976. Alcohol consumption and alcohol problems in demographic groups. Reports from the Social Research Institute of Alcohol Studies No. 114. Helsinki 1978: 1-127. 
5 Simpura J. Drinking occasions and changes in drinking habits in Finland from 1969 to 1976. Alkoholipolitiikka 1978; 43:237-45.

6 Puska P, Tuomilehto J, Salonen J, et al. Changes in coronary risk factors during comprehensive five-year community programme to control cardiovascular diseases (North Karelia project). Br Med J 1979; 2:1173-8.

7 Nikiforow R, Hokkanen E. Effects of headache on working ability: A survey of an urban and a rural population in northern Finland. Headache 1979; 19:214-8.

8 Aho K. Incidence, profile and early prognosis of stroke. Dissertation, Helsinki 1975.

9 Klatsky AL, Friedman GD, Siegelaub AB, Gérard MJ. Alcohol consumption and blood pressure. Kaiser-Permanente Multiphasic Health
Examination Data. $N$ Engl J Med 1977; 296: 1194-200.

10 Klatsky AL, Friedman GD, Siegelaub AB. Alcohol consumption among white, black, or Oriental men and women. Kaiser-Permanente Multiphasic Health Examination Data. Amer J Epidem 1977; 105:311-23.

11 McQueen JD, Sklar FK, Posey JB. Autoregulation of cerebral blood flow during alcohol infusion. J Stud Alcohol 1978; 39:1477-87.

12 Weiss MH, Craig JR. The influence of acute ethanol intoxication on intracranial physical dynamics. Bull L A Neurolog Soc 1978; 43:1-5.

13 Hemmingsen R, Barry DI, Hertz MM, Klinken L. Cerebral blood flow and oxygen consumption during ethanol withdrawal in the rat. Brain Res 1979; 173:259-69. 